\title{
Eulogy to an element
}

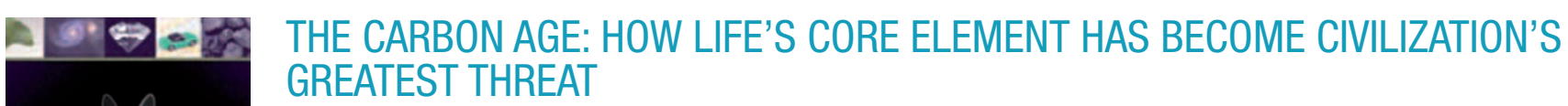

by Eric Roston

Walker \& Company: 2008. 320pp. US\$25.99

What is carbon? Although this remarkable element has recently become something of a media celebrity, few who write about it will have thought too deeply about its origins - and its significance in the wider universe. Eric Roston is an exception, and his stimulating, detailed and thoroughly informative book provides a welcome slew of context for the humdrum daily dose of 'low-carbon this, high-carbon that' now peppering the newspapers.

Sometime after the Big Bang, carbon began its existence in stars. In that sense we are all stardust, as Carl Sagan (and New Age hippies) would have it - or nuclear waste, in Simon Singh's rather wittier take. Nuclear fusion in stars such as the Sun combines hydrogen with more hydrogen to make helium, but it isn't as simple as that: a great deal else happens besides. Several steps down in the fusion process, after the initial hydrogen has been expended, carbon appears. Together with other commonly found Earth elements, carbon can be thought of as the 'ash' of helium fusion.

Yet its unique properties have given carbon a starring role in the story of life. At an atomic level, its electrons break and form new bonds relatively easily - allowing it to be rather promiscuous in the number of molecules it contributes to. Thus, as Roston reveals, even though carbon "doesn't even make the top ten list of earthly elements ... it appears in all but about 100,000 of the more than 33 million known variety of substances." Even by itself it is highly varied.

Diamond, pure elemental carbon, is the hardest natural mineral in existence and conducts heat well but electricity poorly, whereas graphite, also pure carbon, is an extremely soft substance that does almost the reverse.
But carbon really gains prominence from the properties it takes on when combined with other elements. Carbon appears in all amino acids, the essential building blocks of life. How self-replicating organisms first appeared out of the supposed 'primordial soup' is still a matter of debate - and Roston devotes more than a dozen highly detailed pages to it - but carbon is essential in their survival. It supplies much of the matter from which living cells are built, as well as much of the energy, through carbohydrates, that is needed to fuel them.

The appearance of life sets the stage for the next great act in the drama: living beings have in turn dramatically altered the elemental cycles of our planet. This first came about with the arrival of cyanobacteria, which created an oxygenrich atmosphere. Later the evolution of oxygen-respiring marine and terrestrial organisms changed the cycling of nitrogen, phosphate and other chemicals almost beyond recognition.

The rest, as they say, is history. As the sun heats up, living organisms - mainly plants, both on land and in the oceans - sequester carbon in coal and oil deposits, removing it from the Earth's atmosphere for millions of years and helping to prevent a runaway greenhouse like the one on Venus some 3 to 4 billion years ago. Enter the hubristically self-named Homo sapiens, then the internal combustion engine and other paraphernalia of the Industrial Revolution, turning up the planetary thermostat in the blink of a geological eye by burning carbon dug up from safe storage underground.

Though Roston's book starts its history of carbon with the birth of the universe, it is oddly structured and far from chronological. There is a whole discursive chapter on the gingko tree, which - although a fascinating tree - doesn't quite carry the narrative. Later chapters diverge into the chemistry of synthetic polymers such as nylon and polyester before returning to a more familiar tale, the discovery of the heat-trapping properties of greenhouse gases.

The Carbon Age has clearly been a massive labour of love - the acknowledgements reveal that Roston took a hefty two years just to research and structure the proposal before putting pen to paper for the real thing. It shows: he displays an exhaustive knowledge of some very complex areas in organic chemistry and atomic physics. I was surprised to read that he has spent most of his career at Time magazine rather than in the halls of academia. But this makes the book's main drawback all the more perplexing. Getting too close to his subject, the author fails to make many parts of the book reasonably comprehensible to any but the most determined layperson.

Take the following sentence, chosen pretty much at random: "Given the tendency of phospholipid vesicles to self-assemble and of RNA to code, catalyze, and select precise targets, Szostak's lab has embedded functioning RNAs within vesicles, as a potential segue toward the first synthetic organisms." There's nothing wrong with this sentence. Go over it a couple of times, in context, concentrating properly, and it makes perfect sense. But it isn't exactly easy reading for the beach.

There are also one or two glaring errors, and it is a shame to see Roston's careful precision mixed up with statements such as the one declaring the Paleocene-Eocene Thermal Maximum - the super-greenhouse spike 55 million years ago - "one of the 
Earth's five great extinctions". The period did see a minor extinction, particularly in the seas, but nothing on the scale of the Cretaceous-Tertiary or end-Permian wipe-outs, as a cursory fact-check would have shown. These things happen, of course - has any book ever been entirely free of mistakes? - but they do make one more cautious about accepting at face value other statements in areas where the reader may have less familiarity.

That said, The Carbon Age is well worth getting stuck into, precisely because of its wide-ranging, interdisciplinary approach. Few experts on mitochondrial DNA will be able to read the chapter on carbon's stellar-fusion origins without learning something useful, and astronomers might find out a thing or two about evolution that they, in turn, didn't know. There are some great bits of information to impress your friends at parties: who knew that in the time it takes to read this sentence, your cells make 17 million billion base pairs of DNA? Thank you, Eric Roston. Now I'm going to read the book again, in a quiet room, much more slowly.

Published online: 21 August 2008

\section{doi:10.1038/climate.2008.85}

\section{Mark Lynas}

Mark Lynas is a columnist for the New Statesman. His most recent book, Six Degrees: Our Future on a Hotter Planet, won the 2008 Royal Society Prize for Science Books.

e-mail:marklynas@zetnet.co.uk

\section{SNAPSHOT}

\section{Olympic observers}

For much of August, Beijing switched off many of the engines that churn out its infamous pollution - and atmospheric scientists are waiting downwind to find out what happens.

In an effort to make the air healthier for athletes competing in the Summer Olympics - and clean up China's image for the international press - Chinese officials ordered what they called a 'great shutdown'. For the duration of the games, which ran from August 3 to 24, half of Beijing's several million cars were barred from the road, and its factories and power plants were expected to cut activity by up to 30 per cent.

In effect, the Olympics organizers performed a tantalizing experiment, reducing regional emissions of soot and other aerosol pollutants on a scale that only climate modellers could dream of before now. On August 9, scientists from the Scripps Institution of Oceanography at the University of California, San Diego, began launching small unmanned planes (pictured) that will monitor the results of this experiment through the end of September.

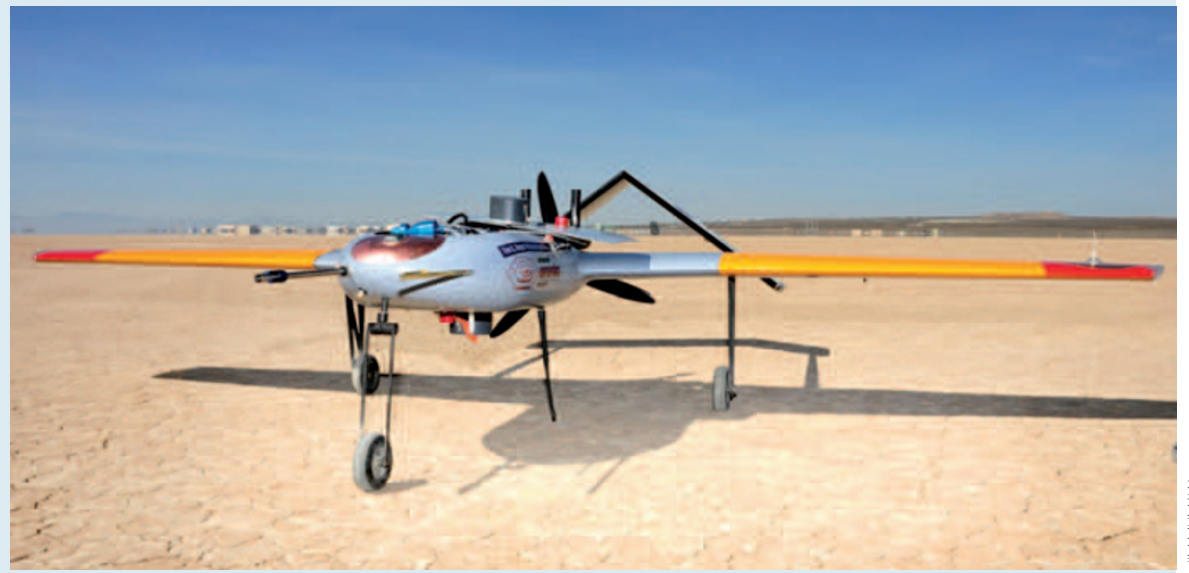

In charge of the project is atmospheric scientist Veerabhadran Ramanathan, who last year reported with co-authors that aerosols in 'brown clouds' make a large contribution to regional warming, among other effects (Nature 448, 575-578; 2007). Taking off from the South Korean island of Cheju, about 1,165 kilometres southeast of the Chinese capital, instruments on the airborne labs will gauge how the Olympian edicts have altered the quantity and size of particles drifting from Beijing. Specific sensors on the Cheju fleet will measure how those particles in turn affect meteorological conditions such as temperature, humidity and the sunlight that filters through the haze, and will tease out the impacts of different pollutants.

Unlike long-lived greenhouse gases, soot sifts out of the atmosphere in only a few weeks, so the outcome of Beijing's temporary industrial shutdown could be striking.

Published online: 28 August 2008

doi:10.1038/climate.2008.87

Anna Barnett 